\title{
A metodologia da problematização como estratégia de ensino em curso superior
}

\author{
The problematization methodology as a higher course teaching strategy \\ Metodología de la problematización como estrategia de enseñanza en un curso superior
}

Recebido: 21/09/2021 | Revisado: 27/09/2021 | Aceito: 30/09/2021 | Publicado: 03/10/2021

\author{
Gisele Leles Souza \\ ORCID: https://orcid.org/0000-0003-2239-2052 \\ Faculdade Independente do Nordeste, Brasil \\ E-mail: giselelelesbernades@gmail.com \\ Luana Araújo dos Reis \\ ORCID: https://orcid.org/0000-0002-9263-083X \\ Faculdade Independente do Nordeste, Brasil \\ E-mail: luanareis@fainor.com.br \\ Thalyan Oliveira Malheiro \\ ORCID: https://orcid.org/0000-0003-0271-4667 \\ Universidade do Estado da Bahia, Brasil \\ E-mail: thalyanoliveira@gmail.com
}

\begin{abstract}
Resumo
Aprendizagem Baseada em Problemas é um método instrucional (e curricular) centrado no estudante, capacitando os aprendizes a conduzir a pesquisa, integrando a teoria à prática e aplicando o conhecimento e habilidades para desenvolver uma solução viável para o problema definido. Este artigo trata-se de um estudo descritivo, exploratório de abordagem quantitativa, realizado através de um questionário online com 34 estudantes do curso superior de Estética e Cosmética. Os dados foram analisados através da análise descritiva simples e apresentados em gráficos. O estudo concluiu, através da percepção dos estudantes, que o método PBL proporciona o desenvolvimento do raciocínio clínico e da habilidade em estudo autodirigido, que são capacidades essenciais para a atuação profissional.

Palavras-chave: Aprendizado baseado em problemas; Ensino; Educação.
\end{abstract}

\begin{abstract}
Problem-based learning (PBL) is a student-centered instructional (and curricular) method, empowering learners to conduct research, integrating theory into practice and applying knowledge and skills to develop a viable solution to the defined problem. This article deals with a descriptive, exploratory study with a quantitative approach, carried out through an online questionnaire with 34 students of the higher course of Aesthetics and Cosmetics. The data were analyzed through simple descriptive analysis and presented in graphs. The study concluded, through the students' perception, that the PBL method provides the development of clinical reasoning and self-directed study skills, which are essential capacities for professional performance.
\end{abstract}

Keywords: Problem based learning; Teaching; Education.

\section{Resumen}

Problem-Based Learning (PBL), o Aprendizaje Basado en Problemas, es un método instruccional (y curricular) centrado en el estudiante, capacitando a los aprendices a conducir la investigación, integrando la teoría a la práctica y aplicando el conocimiento y habilidades para desarrollar una solución viable para el problema definido. Este artículo se trata de un estudio descriptivo, exploratorio de abordaje cuantitativo realizado a través de un cuestionario online con 34 estudiantes del curso superior de Estética y Cosmética. Los datos fueron analizados a través del análisis descriptivo simple y presentados en gráficos. El estudio concluyó, a través de la percepción de los estudiantes, que el método PBL proporciona el desarrollo del raciocinio clínico y de la habilidad en estudio autodirigido, que son capacidades esenciales para la actuación profesional.

Palabras clave: Aprendizaje basado en problemas. Enseñanza. Educación.

\section{Introdução}

A educação é um componente fundamental do processo de tomada de decisão de cada indivíduo, que se baseia essencialmente na aquisição e no uso crítico do conhecimento. Costa (2018) define a graduação como um estágio do processo 
de formação que deve ser consecutivo para enfrentar a frequente mudança na produção de conhecimentos, e uma formação que incorpore os processos de aprender a aprender e que busque atender às exigências da sociedade, além de preconizar uma formação de profissionais autônomos e flexíveis. Portanto, o método empregado para educar afeta profundamente os empreendimentos sociais, culturais e profissionais de cada pessoa (Jiménez-saiz \& Rosace, 2019).

O Curso Superior de Tecnologia em Estética e Cosmética está de acordo com as Diretrizes Curriculares Nacionais (DCN's), definidas pelo Conselho Nacional de Educação (CNE) para formação dos tecnólogos, com foco no domínio e na aplicação de conhecimentos científicos e tecnológicos em áreas específicas de conhecimento relacionado ao eixo tecnológico de Ambiente, Saúde e Segurança. O Ministério da Educação e Cultura (MEC), através das DCN's, destaca que:

[...] "o projeto político-pedagógico seja construído coletivamente; a interdisciplinaridade conforme o processo ensinoaprendizagem; haja valorização das dimensões éticas e humanísticas; a inserção de professores e estudantes nos serviços existentes nas respectivas localidades fortaleça a parceria ensino serviço; haja diversificação de cenários; a gestão desenvolva um sistema de corresponsabilização, de avaliação e acompanhamento livre de medos; e a seleção dos conteúdos seja orientada às necessidades sociais" (Silva et al., 2008, p. 20).

Com base nesse contexto, o uso de metodologias que estimulem a reflexão sobre a realidade social e que promovam o "aprender a aprender" têm sido adotadas por muitas universidades. Estratégias de aprendizado ativas atraem os estudantes para uma discussão lógica e racional e para o hábito de analisar situações criticamente (Adler \& Gallian, 2018; Doherty et al., 2018).

Metodologias ativas são formas de ensino que utilizam experiências reais ou simuladas, visando estimular a solução de desafios advindos da prática social e clínica, em diferentes contextos, e que proporcionam a formação de um indivíduo ativo, crítico, por meio de uma aprendizagem significativa. Há inúmeras práticas pedagógicas que contribuem para a formação moral do indivíduo, como o Aprendizado em Serviço (ApS), a Construção de Narrativas Reflexivas, a Discussão de Dilemas Morais, o Estudo de Caso, a Metodologia da Problematização, as Situações Problema (SPs) e as Estações de Simulação da Prática Profissional ou Habilidades, Atitudes Clínicas e a Aprendizagem Baseada em Problemas ou Problem Based Learning (PBL). Essas são algumas estratégias de metodologias ativas de ensino aprendizagem que estimulam o estudante a adquirir competências, não só técnicas, mas também humanísticas e éticas (Berbel, 2011; Pinheiro et al., 2011).

A metodologia de Aprendizagem Baseada em Problemas (PBL) utiliza problemas reais como gatilhos e cria um ambiente de aprendizado que motiva os estudantes a se envolverem ativamente e pensarem criticamente. Essa autoaprendizagem desempenha um papel vital na vida do graduando, pois de acordo com esse método, o conhecimento absorvido seria retido e aplicado para a solução de problemas em sua futura prática clínica (Al-madi et al.,2018).

Diante dessa problemática, para a realização deste estudo partimos da seguinte questão norteadora: qual a percepção dos estudantes do curso superior de Estética e Cosmética acerca da eficácia da metodologia da Problematização (PBL)? Nessa perspectiva, o objetivo deste estudo foi conhecer a percepção dos estudantes do curso superior de Estética e Cosmética acerca da eficácia da metodologia da Problematização (PBL).

\subsection{Educação superior: processo formativo}

Há uma demanda crescente por educação superior e um reconhecimento sobre sua importância para o desenvolvimento econômico e social. Sem dúvida, a educação superior vem dando amplas demonstrações de sua importância para promover transformações na sociedade, por isso passou a fazer parte do rol de temas considerados prioritários e estratégicos para o futuro das nações. Berbel (1995) descreve a educação superior no Brasil como um processo que vai além da capacitação profissional, segundo ele a formação superior exerce significativa influência na construção e reconstrução do saber, no preparo do cidadão e sua participação na construção de uma sociedade justa, livre e desenvolvida. Com relação ao 
ensino superior, Georgen (2008) salienta que esse tem como tarefa fazer a intermediação entre o indivíduo e a sociedade, preparando-o, em termos de conhecimentos, habilidades e capacidade de aprendizagem permanente, para atender às demandas do mercado de trabalho (Neves, 2007).

As mudanças na sociedade moderna, no entanto, têm levado, de modo cada vez mais contundente, a discussões relacionadas à formação dos profissionais de saúde e sobre a eficiência dos métodos de ensino e aprendizagem dentro das universidades, considerando, em especial, a multiplicidade das demandas oriundas de um mercado cada vez mais competitivo. As aulas expositivas tradicionais têm estado mais voltadas para a transmissão de conhecimentos, nas quais o conteúdo a ser aprendido é apresentado pelos professores aos estudantes em sua forma final, privando-os do exercício das habilidades intelectuais mais complexas como a aplicação, análise, síntese e julgamento (Borochovicius, 2014; Dias-lima et al., 2019).

O pressuposto é o de que o conteúdo ensinado, por si só, não levará à formação do profissional habilitado para enfrentar os desafios do mundo contemporâneo. A articulação, a preparação e a contextualização são o centro do processo de aprendizagem para que os conhecimentos construídos e assimilados possam ser colocados em prática de forma eficiente. Consequentemente torna-se impreterível que o processo de ensino-aprendizagem forneça ao estudante as ferramentas necessárias para que ele possa desenvolver suas aptidões, a partir da articulação de habilidades, tais como: instigar o que aprendeu desenvolver autonomia intelectual diante de um desafio profissional, saber transformar informações em conhecimentos pessoais, fazer análises e sínteses, relacionar aprendizado e tirar conclusões. Cabendo, portanto, às instituições responsáveis pela formação desses futuros profissionais (gestores acadêmicos, professores, pesquisadores e coordenadores de curso) o encargo de inovar em ações educacionais metodológicas (Moraes, 2006; Projeto, 2017).

\subsection{Processo ensino aprendizagem no curso de estética e cosmética}

As metodologias de ensino tradicionais, cheias de conteúdo, que ainda são aplicadas em disciplinas dos cursos superiores de Tecnologia em Estética e Cosmética, favorecem a memorização de conteúdos, mas não estimulam o desenvolvimento de competências, habilidades e atitudes requeridas para o pleno exercício da profissão. No modelo tradicional, ainda predominante, a formação tem por base uma pedagogia que não estimula adequadamente a autonomia, a capacidade de análise, julgamento e avaliação, bem como raciocínio crítico, investigativo e criativo. Nesse padrão, os métodos tradicionais de ensino são caracterizados pela transmissão verticalizada de conhecimentos e pela ênfase na memorização em prejuízo da reflexão crítica, baseando-se, essencialmente, em aulas expositivas, em que o professor é o detentor de conhecimentos e grande protagonista, cabendo aos estudantes repetir os conteúdos memorizados nas provas classificatórias. Esse sistema, no qual o estudante atua quase sempre de forma passiva, dificulta a sua participação no processo de busca e sedimentação do conhecimento, elemento essencial para o desenvolvimento de mentes críticas e inovadoras (Maya et al., 2017; Cruz, 2019).

O Modelo PBL, por outro lado, desafia professores e estudantes a assumirem novas condutas, inclusive no processo de avaliação. Esta avaliação deve ser sistemática e se constitui em uma importante ferramenta em todo processo de Ensino Aprendizagem. O processo avaliativo no método PBL está a serviço da construção do conhecimento, entendimento, harmonização, aceitação das diferenças, tendo como premissa uma melhor qualidade de vida. Referindo-se ao processo avaliativo por uma perspectiva mais atual, Oliveira (2012, p. 302) aborda que: [...] “a auto avaliação tem como pressuposto a busca de metas pessoais onde o estudante se responsabiliza pelo seu aprendizado, ocasionando um sujeito ativo, para aprender e participar da ação educativa" (Dias-lima et al., 2019).

Assim sendo, Lacerda e Santos (2018) defendem que os métodos não tradicionais de ensino, quando bem estruturados e fundamentados, podem ser a resposta para a deficiência acadêmica atual, auxiliando na construção de uma formação de nível 
superior integral, agregando competências e preparando profissionais melhores e mais competitivos para o mercado de trabalho.

A atuação do professor no curso de Estética e Cosmética necessita de harmonia entre a teoria e a prática, no que diz respeito aos conteúdos ministrados em sala de aula. Uma abordagem didática e metodológica correta proporciona a transmissão do conhecimento de forma mais efetiva, preparando e capacitando o profissional para o mercado de trabalho. Assim, os cursos de Estética e Cosmética exigem algo a mais nas suas estratégias de ensino, requerendo-se dos professores domínio na aplicação das técnicas e suas possíveis reações, facilitando por meio de experimentos práticos a aprendizagem e compreensão dos conteúdos teóricos pelos estudantes. Com isso, as aulas ministradas se tornam mais dinâmicas, criativas e interessantes, permitindo aos egressos uma melhor atuação no mercado de trabalho ao início da carreira. Nesse contexto, o PBL contribui para o ensino, pois apoia uma relação entre aprendizagem e experiência traduzida na forma como os estudantes aprendem, utilizando a resolução de problemas e a reflexão sobre suas experiências, ajudando os estudantes a desenvolverem estratégias e construírem conhecimentos, além de apoiá-los na sua capacidade de serem estudantes ativos e responsáveis pela própria aprendizagem em sua completa capacidade. O PBL ainda permite que esses futuros profissionais desenvolvam abordagens inovadoras e habilidades para enfrentá-los com êxito (Carvalho, 2016; Adler \& Gallian; 2018).

\subsection{Aprendizagem baseada em problemas (PBL)}

No Brasil, o Método PBL foi implantado pela primeira vez na Escola de Saúde Pública do Ceará em 1993, depois na Faculdade de Medicina de Marília (FAMEMA), em 1997, e no curso de Ciências Médicas da Universidade de Londrina (UEL), em 1998. Atualmente vem sendo empregado em diversas universidades do mundo, assim como no Brasil, principalmente na área da saúde, nos cursos de Medicina, Enfermagem, Pedagogia, Biomedicina, Fisioterapia, bem como no Curso de Estética e Cosmética (Pinheiro, 2011; Freitas, 2012; Jiménez-saiz et al., 2012; Al-madi, 2018; ibrahim et al., 2018).

O Problem Based Learning (PBL) é um método de aprendizagem que trabalha com situações-problemas elaboradas por um professor ou uma equipe de professores, com o intuito de estimular processos cognitivos em relação a um determinado assunto. Os problemas são cuidadosamente planejados com a finalidade de integrar os conteúdos teóricos e são distribuídos na matriz curricular de acordo com uma sequência de aprendizado, ou seja, com graus crescentes de complexidade (Marques, 2018).

Uma característica marcante dessa abordagem ativa de educação é que ela provoca uma inversão de papéis, colocando o estudante como foco central e transformando o professor ou tutor em posição de facilitador, fornecendo 'andaimes' para dar estrutura e apoio aos estudantes, permitindo o aprendizado autodirigido. Portanto, o tutor do PBL tem um papel fundamental na influência do resultado bem-sucedido do PBL para os estudantes (Dohenty, 2018).

Embora o PBL possa assumir várias formas, a depender da instituição e do professor, para Savery (2006, p. 12) ele é construído com base nos seguintes princípios: "problemas relevantes e autênticos formam a base do ensino e da aprendizagem; os estudantes como atores centrais e buscadores ativos de conhecimento; e aprendendo através da colaboração e discussões". Os recursos essenciais do PBL incluem uma abordagem interdisciplinar, atividades autênticas que são valorizadas no mundo real, problemas mal estruturados, colaboração dos estudantes, informações coletadas individualmente, processo de tomada de decisões em grupos, discussão de princípios e objetivos e autoatendimento (Borochovicius \& Tortella, 2014).

\section{Metodologia}

Trata-se de estudo descritivo, exploratório de abordagem quantitativa, compreendendo que a pesquisa do tipo descritiva visa levantar opiniões de um determinado grupo. E a pesquisa do tipo quantitativa, segundo Diehl (2004), é aquela que apresenta pelo uso da quantificação, tanto na coleta quanto no tratamento das informações, a utilização de técnicas 
estatísticas, objetivando resultados que evitem possíveis distorções de análise e interpretação, possibilitando uma maior margem de segurança (Hartmut, 2006; Rufatto \& Carneiro, 2012).

Os dados foram coletados através de um questionário online, nos meses de fevereiro e março de 2020, com estudantes do curso superior de Estética e Cosmética. Faleiros (2016) argumenta que uso de recursos virtuais para a realização de pesquisas na área de saúde representa uma alternativa econômica e com maior velocidade de informação e produção científica. Além disso, as pesquisas pela internet proporcionam maior praticidade e comodidade aos participantes do estudo, podendo resultar na melhora do número de respostas obtidas.

Com o uso de formulários online é possível, atualmente, a elaboração, publicação e coleta de dados em um tempo mínimo. Dessa forma, o "pesquisador não está mais limitado pelas restrições de tempo, custo e distância, possuindo um acesso mundial praticamente instantâneo, com despesas mínimas" (Freitas et al., 2004, p. 12). Ademais, a utilização de formulários online permite o uso de interfaces mais interativas e ricas, tanto na coleta quanto na apresentação dos dados (Foina, 2011). A possibilidade de desenvolvimento de formulário próprio permite não apenas a definição dos aspectos visuais do produto final, mas, de maneira tão importante quanto, também o funcionamento e a usabilidade da estrutura produzida.

O estudo foi composto por 34 estudantes do curso superior de Estética e Cosmética de uma instituição de ensino superior privada na região Sudoeste da Bahia, Brasil. Como critérios de inclusão elencou-se: estudantes matriculados nas disciplinas de Afecções Cutâneas, Envelhecimento Cutâneo e Pré e Pós Operatório, ou que já tivessem cursado as disciplinas anteriormente no decorrer do curso, visto que no local da pesquisa apenas esses três componentes são ministrados através do método PBL.

O contato com os participantes ocorreu virtualmente através de uma lista disponibilizada pela coordenação do curso, contendo os e-mails dos estudantes. Nos e-mails enviados pela pesquisadora, além de disponibilizar o link do questionário online, também constava o Termo de Consentimento Livre e Esclarecido informando ao participante que a utilização das informações prestadas ao pesquisador seria utilizada apenas com fins acadêmico-científicos, bem como informações sobre os objetivos e relevância da pesquisa, também informava sobre o seu direito de participar ou não, da autonomia de desistir em qualquer fase, devendo o mesmo expressar esta intenção à pesquisadora através do telefone disponibilizado, dispensando, portanto, qualquer contato direto com os participantes. Ressaltamos que o projeto que deu origem a este estudo foi aprovado pelo Comitê de Ética em Pesquisa da Faculdade Independente do Nordeste (FAINOR) sob o Parecer no 3.758.618, em 10 de dezembro de 2019.

Ao acessar ao link o participante era direcionado para o questionário online disponível no Google Forms. O questionário continha 10 questões sobre a abordagem PBL. Os participantes foram convidados a indicar concordância em uma escala Likert de quatro pontos organizada da seguinte forma: concordo totalmente (4), concordo (3), discordo (2) e discordo totalmente (1). Quanto maior a pontuação, maior a probabilidade dos estudantes considerarem a abordagem PBL eficaz. Os itens do questionário foram testados quanto à sua confiabilidade, validade e para garantir que as perguntas não estivessem medindo o mesmo conceito pressuposto antes do estudo.

Para todos os tipos de questões, o Google Forms trás a possibilidade de tornar as perguntas obrigatórias, de modo que o questionário só poderá ser enviado se todas as questões obrigatórias estiverem respondidas. Quando preenchido pelos respondentes, as respostas aparecem imediatamente na página do Google Forms do usuário que os criou. Essa é uma das principais vantagens no seu uso, a visualização dos dados coletados. As respostas aparecem organizadas em uma tabela, onde cada coluna corresponde às resoluções de uma questão e cada linha corresponde a um respondente. Essa planilha pode ser exportada em diversos formatos, inclusive como uma planilha Excel conforme Figura 1. 
Figura 1: Resultados gerados pelo Google Forms em formato de planilha no Excel.

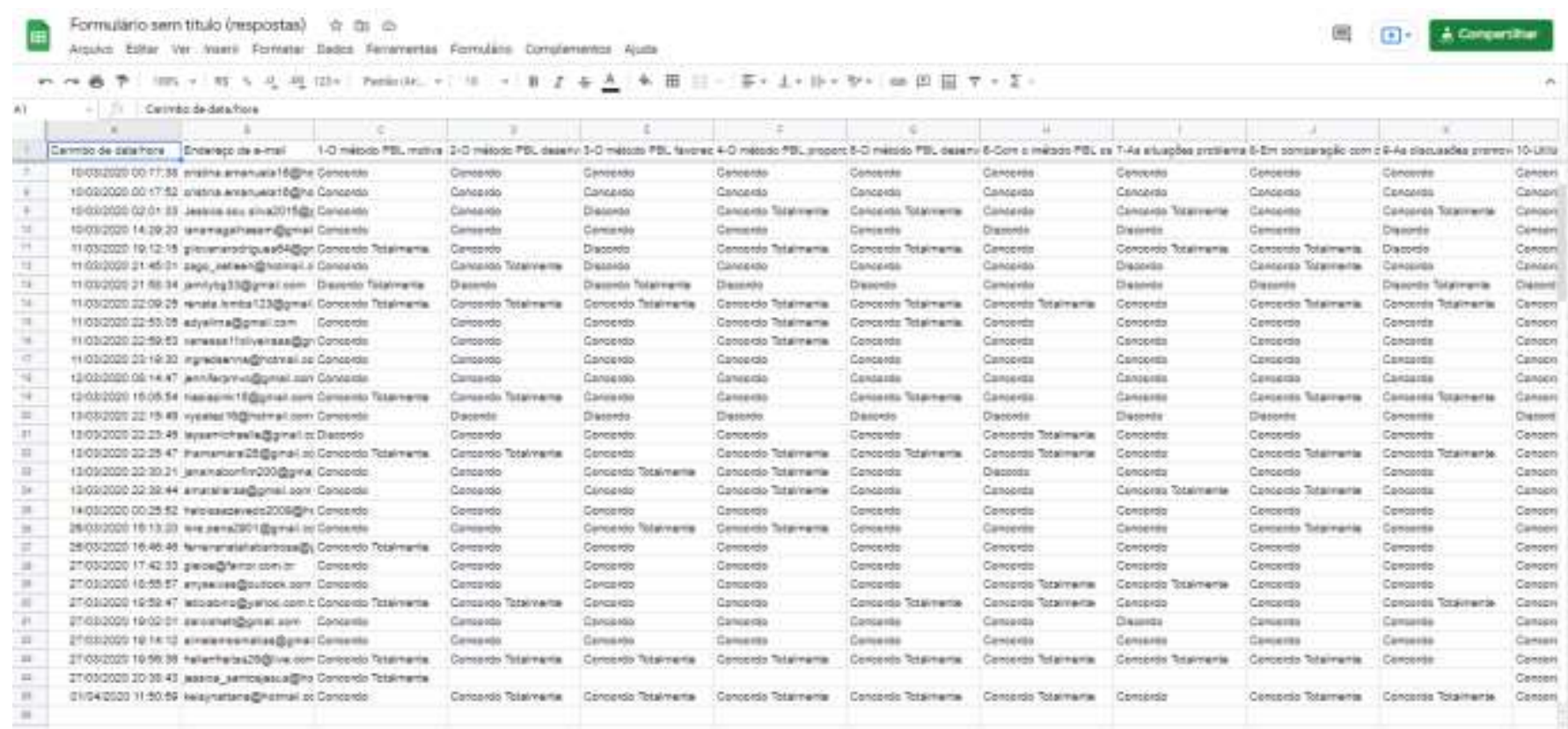

Fonte: Dados da pesquisa (2020).

A plataforma Google Forms disponibiliza, também, a apresentação dos dados dispostos em gráficos (Google, 2017). Para este estudo, optamos pela visualização dos dados em gráficos, justamente por ser mais agradável, facilitando a análise dos dados, que se deu através da análise descritiva simples.

\section{Resultados}

Através das informações coletadas, foi possível conhecer a percepção dos estudantes do curso Tecnológico Superior em Estética e Cosmética, que ao serem questionados se o método PBL motiva e estimula os estudantes à aprendizagem responderam que concordam (58,8\%). Para 63,6\% dos participantes o método também desenvolve o senso colaborativo entre os estudantes, tornando-os aprendizes independentes, estimulados para uma abordagem centrada no estudante. 57,6\% dos participantes referem que o método PBL favorece o desenvolvimento da habilidade para trabalhar em equipe.

Para os participantes desta pesquisa o método PBL proporciona o desenvolvimento do raciocínio clínico e da habilidade em estudo autodirigido, que são capacidades essenciais para a atuação profissional, conforme pode ser observado no gráfico abaixo: 
Gráfico 1 - Método PBL e o desenvolvimento do raciocínio clínico e da habilidade em estudo autodirigido.

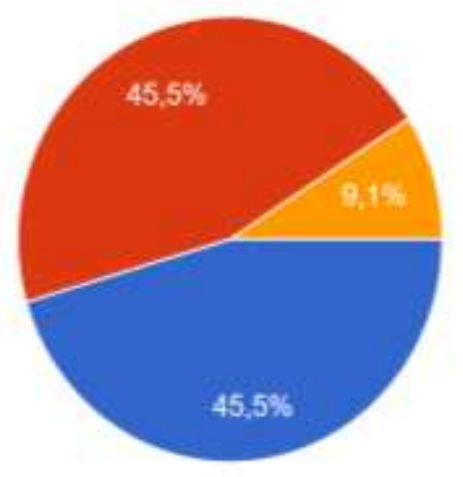

Concordo Totalmente

Concordo

Discordo

Discordo Totalmente

Fonte: Dados da pesquisa (2020).

54,5\% percebem o método PBL como importante para o estudante desenvolver a capacidade de discussão a partir de uma reflexão crítica apoiada na necessidade da leitura e interpretação para resolução dos problemas. Para a maioria dos participantes, 57,6\%, com o método PBL os estudantes trabalham descobrindo o limiar do conhecimento existente e busca ampliá-lo através de questionamentos, estudo centrado e autodirigido, reflexões e elaborações do novo conhecimento no contexto de um problema. 54,5\% dos participantes referem, também, que as situações problematizadoras de aprendizagem preparam o estudante para resolver adequadamente problemas relativos à sua profissão.

Quando questionados em relação ao comparativo entre o método tradicional de ensino e o método PBL, a maioria dos participantes desta pesquisa referiu que o método PBL proporciona uma melhor formação através de uma aprendizagem dinâmica, que reflete situações reais da vida profissional, conforme gráfico abaixo:

Gráfico 2 - O método PBL proporciona uma melhor formação através de uma aprendizagem dinâmica, que reflete situações reais da vida profissional.

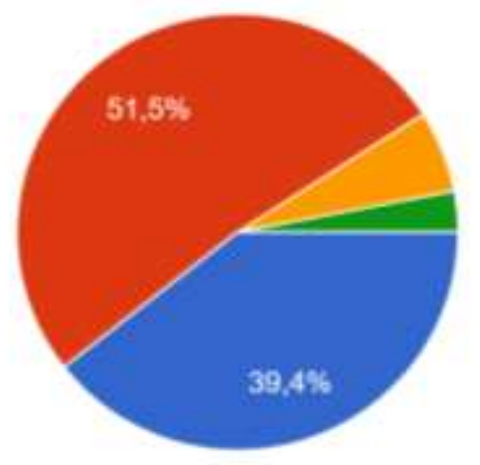

Concordo Totalmente

Concordo

Discordo

Discordo Totaimente

Fonte: Dados da pesquisa (2020).

Em relação às discussões promovidas através do método PBL, 57,6\% dos participantes concordam que estas prendem a atenção dos estudantes, desenvolvendo a capacidade de comunicação oral e maior integração entre estudantes e professores, conforme segue: 
Gráfico 3 - O PBL prende a atenção dos estudantes, desenvolvendo a capacidade de comunicação oral e maior integração entre estudantes e professores.

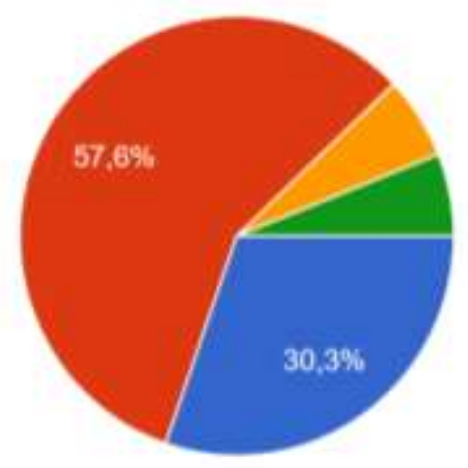

Concordo Totaimente

Concordo

Discordo

Discordo Totaimente

Fonte: Dados da pesquisa (2020).

Por fim, a maioria dos estudantes entrevistados concordou que utilizando o método PBL a aprendizagem é maior e mais significativa, conforme gráfico que segue:

Gráfico 4 - Utilizando o método PBL a aprendizagem é maior e mais significativa.
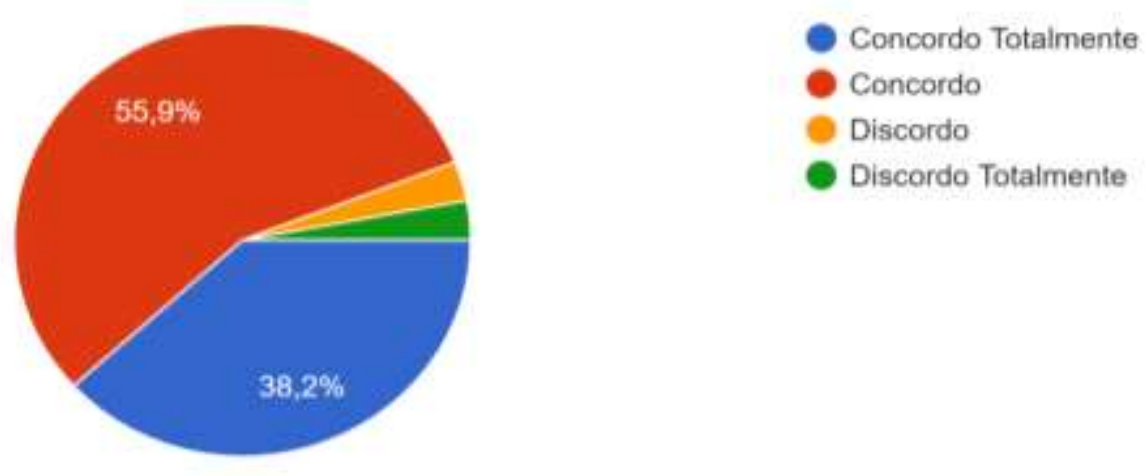

Fonte: Dados da pesquisa (2020).

\section{Discussão}

O método PBL é incentivado para utilização nos cursos de nível superior, pois abrange a aprendizagem ativa com objetivos de aprendizagem predefinidos. Os cenários clínicos da vida real são usados como gatilhos para motivar os estudantes a assumirem responsabilidade por seu próprio aprendizado, o que, em última análise, melhora sua autoconfiança e habilidades em praticamente lidar com essas situações no futuro (Freeman, et al., 2014).

No curso de Estética e Cosmética avaliado, as disciplinas de Afecções Cutâneas, Envelhecimento Cutâneo e Pré e Pós-Operatório foram elaboradas de tal maneira a incorporar as pedagogias centradas no professor e no estudante. Isso foi evidenciado nas respostas dos participantes, quando estes mostraram maior motivação e estímulo à aprendizagem proporcionando o desenvolvimento do raciocínio clínico e da habilidade em estudo autodirigido, conforme apresentado no Gráfico 1. Corroborando com tais resultados, Zahid (2018) em seu relato mostrou a capacidade do PBL em aprimorar o pensamento crítico, melhorar as relações interpessoais, resultando em maior motivação para o estudo. 
Segundo Khoshnevisas et al. (2014), os estudantes preferem o método PBL por causa do aumento da motivação, aprendizado de qualidade, retenção de conhecimento, atratividade das aulas e utilidade prática dos conteúdos.

Em relação ao desenvolvimento do senso colaborativo entre os estudantes e da habilidade para trabalhar em equipe ao mesmo tempo em que os tornara aprendizes independentes, estimulados para uma abordagem centrada em si próprio. Estes resultados corroboram com os achados da pesquisa realizada por Junior e Kanikadan (2019), onde os estudantes pesquisados afirmaram que o PBL demanda de maior interação interpessoal o que favorece o surgimento de conflitos, permitindo de forma abrangente o crescimento individual em singularidade, onde o respeito, senso crítico e resiliência tornam-se ferramentas necessárias para superação desses problemas. Estudo realizado por Deslauriersa et al. (2019) apontou que o PBL é uma maneira eficaz de melhorar o pensamento crítico, aprimorando o trabalho em equipe. Os participantes ainda relataram aprender a trabalhar com sucesso com outros estudantes de diferentes áreas sociais, além disso, eles sentiram que o trabalho em grupo que ajuda a interagir com outros é o melhor método de aprendizado.

Nesta pesquisa, os estudantes de Estética e Cosmética descobriram ter efeitos positivos no que tange ao quesito desenvolvimento da capacidade de discussão, a partir de uma reflexão crítica apoiada na necessidade da leitura e interpretação para resolução de situações problematizadoras de aprendizagem, que preparam o estudante para resolver adequadamente problemas relativos à sua profissão, conforme ilustrado no Gráfico 2. Junior e Kanikadan (2019) em sua pesquisa realizada com estudantes do $1^{\circ}$ ao $4^{\circ}$ ano do curso de medicina, levantou que o método PBL demonstrou-se capaz de estimular a aquisição de habilidades e competências importantes para o profissional médico, que em muito precisa solucionar problemáticas. De certa forma, as situações propostas mostram-se capazes de direcionar e instigar a busca pelo conhecimento.

Em pesquisa realizada por Wang (2016), conclui-se que a abordagem PBL oferece aos participantes oportunidades de serem criativos, colaborarem e assumirem responsabilidade pessoal e, de várias maneiras, se assemelharem a algumas das características de sua prática profissional relacionada à clínica.

Em relação à percepção de que com o PBL os estudantes trabalham descobrindo o limiar do conhecimento existente e busca ampliá-lo através de questionamentos, estudo centrado e autodirigido, reflexões e elaborações do novo conhecimento no contexto de um problema, Silva (2018) refere que a busca ativa do conhecimento é um elemento indispensável na formação profissional para o presente, pois o conhecimento está em constante progresso e as situações práticas propostas pelo método são complexas, exigindo soluções criativas e atuais. Além disso, o método inclui aprendizado de situações reais, permite a reflexão em diferentes dimensões e integra os conteúdos, substituindo o conhecimento fragmentado oferecido pelas disciplinas acadêmicas, o que permite uma abordagem integrativa e ampliada. Essa conclusão endossa os resultados deste estudo.

Ademais, é possível observar no Gráfico 3 que, relacionado às discussões promovidas através do método PBL, os participantes da pesquisa concordam que estas prendem a atenção, desenvolvendo a capacidade de comunicação oral e maior integração entre estudantes e professores. Corroborando, os resultados da pesquisa realizada por Ibrahim et al. (2018), refere que os estudantes foram mais atraentes à abordagem do PBL, pois sentiram-se motivados e estimularam sua atenção na aprendizagem do assunto. Ele justifica dizendo que o PBL cria um ambiente de ensino diferente, tornando o aprendizado divertido, motivado, agradável e tirando os estudantes da rotina chata na sala de aula. O mesmo autor ainda sugere que o PBL oferece aos estudantes melhores habilidades de pensamento crítico, raciocínio, formação de equipes, comunicação, aprendizado autodirigido e sumarização do que as aulas tradicionais.

Por fim, a maioria dos estudantes participantes desta pesquisa referiu que prefere o método PBL ao método tradicional, concordando, ainda, que utilizando o método PBL a aprendizagem é maior e mais significativa, conforme Gráfico 4. Tais resultados assemelham-se com resultados do estudo realizado por Fermozelli et al. (2017) que mostrou que a maioria 
dos estudantes relataram aumento de interesse pelos estudos com a utilização de uma metodologia ativa na disciplina de Patologia, e que esta abordagem promoveu maior integração entre os conteúdos trabalhados e a clínica dos pacientes.

Pesquisa realizada por Kalaian e Kasim (2017) também concluiu que os métodos e atividades de aprendizado em pequenos grupos eram, em média, mais eficazes do que a instrução tradicional baseada em conferências, com efeito médio ponderado significativo.

\section{Considerações Finais}

Através da análise dos resultados e atendendo ao objetivo de conhecer a percepção dos estudantes do curso superior de Estética e Cosmética acerca da eficácia da metodologia da Problematização (PBL), concluímos que o método PBL proporciona o desenvolvimento do raciocínio clínico e da habilidade em estudo autodirigido, que são capacidades essenciais para a atuação profissional. Os resultados evidenciaram, por exemplo, que embora as palestras tradicionais dominem o ensino de graduação por quase um milênio e continuem a ter fortes defensores, as abordagens mais ativas e construtivistas apresentam melhores respostas no desempenho dos estudantes.

Além disso, as mudanças culturais e contemporâneas têm mudado o perfil dos estudantes que ingressam nas universidades e, em particular, no curso de Estética e Cosmética. A visão do estudante universitário da atualidade é muito mais ampla do que a de anos atrás, devido a sua experiência no mercado de trabalho, tornaram-se indivíduos indagativos e informatizados, em busca de conhecimento científico, possuindo, portanto, capacidade suficiente para perceber a inaptidão de um professor ou da metodologia por esta empregada. Ademais, o estudante é capaz, ainda, de discernir e até mesmo discordar de determinadas teorias e didáticas apresentadas por alguns professores, vez que, é na prática que se consolida a teoria e é nesse momento que se tem a oportunidade de verificar a aplicabilidade da mesma.

Correlacionada a essa situação, considera-se que a relação linear tradicional entre professor-estudante deve ser substituída por uma relação dialógica, onde o estudante assume participação ativa e o professor o papel de orientador, visto que a utilização de metodologias ativas no processo de ensino possui desdobramentos que permitem transpor o campo da racionalidade técnica, convocando o estudante ao desenvolvimento de competências profissionais que contribuam para a sua formação. A reflexão sobre sua aplicabilidade, resultados e desdobramentos devem ser considerados ao longo do processo, não tendo um fim em si mesmas.

É importante salientar que a utilização de metodologias ativas representa um desafio para os professores. Contudo, busca-se com os resultados deste estudo encorajar a capacitação dos professores e a crescente inserção dessas metodologias no processo de ensino-aprendizagem nos cursos superiores, sobretudo de Estética e Cosmética, oportunizando aos estudantes alternativas que favoreçam a aprendizagem significativa e duradoura. Afinal, se os futuros profissionais esteticistas e cosmetólogos estarão enfrentando condições desafiadoras e complexas futuramente no mercado de trabalho, o lugar para que possam fazer, refazer, consertar, construir e ressignificar é a Universidade/Faculdade.

A fim de evidenciar os resultados apresentados nesta pesquisa, sugere-se que outros estudos sejam realizados, preferencialmente em cursos distintos, das três grandes áreas. Assim, a utilização das metodologias ativas deixaria de ser um recurso a mais para o processo ensino e aprendizagem, passando a ser visto como uma importante ferramenta didática pedagógica para que o estudante se torne ator da sua própria formação profissional e, consequentemente, com uma maior capacidade crítica, reflexiva e resolutiva. 


\section{Referências}

Adler, M. S. \& Galian, D. M. C. (2018). Escola médica e Sistema Único de Saúde (SUS): criação do curso de medicina da Universidade Federal de São Carlos, SP, Brasil (UFSCar) 17 sob perspectiva de professores e estudantes. Interface. 22(64), 237-249. http://www.scielo.br/pdf/icse/v22 n64/1807-5762-icse1807-576220150455.pdf.

Al-Madi, E., Celur, S. L. \& Nasim, M. (2018). Eficácia da metodologia PBL em um programa de odontologia híbrida para aprimorar o conhecimento e a confiança dos estudantes. (um estudo piloto). BMC Med Educ, Riyadh. 18, 270. https://www.ncbi.nlm.nih.gov/pubmed/30458764.

Berbel, N. A. N. (1995) Metodologia da problematização: uma alternativa metodológica apropriada para o ensino superior. Semina: Cio Soc./Hum., Londrina, 16(2) 9-19. http://www.uel.br/revistas/uel/index.php/seminasoc/article/view/9458/8240.

Borochovicius, E. \& Tortella, J. C. B. (2014) Aprendizagem Baseada em Problemas: um método de ensino-aprendizagem e suas práticas educativas. Ensaio: aval. pol. públ. Educ., 22 (83), 263-294. http://www.scielo.br/pdf/ensaio/v22n83/a02v22n83.pdf>.

Carvalho, K. O. \& Silva, W. O. P. (2016) Procedimentos de ensino do professor no curso de estética e cosmética. Monografia (Especialização em Docência Universitária) - Faculdade Católica de Anápolis. Anápolis, p. 23.

Cruz, P. O et al. (2019) Percepção da Efetividade dos Métodos de Ensino Utilizados em um Curso de Medicina do Nordeste do Brasil. Rev. bras. educ. med., Brasília, 43(2), 40-47. http://www.scielo.br/scielo.php?script=sci_arttext\&pid=S0100-55022019000200040\&lng=pt\&nrm=iso.

Deslauriersa, L. et al. (2019) Measuring actual learning versus feeling of learning in response to being actively engaged in the classroom. PNAS, Berkeley, CA, 116(39), 19251-19257. doi/10.1073/pnas.1821936116.

Dias-lima, A. et al. (2019) Avaliação, Ensinagem e Metodologias Ativas: uma Experiência Vivenciada no Componente Curricular Mecanismos de Agressão e de Defesa, no curso de Medicina da Universidade do Estado da Bahia, Brasil. Rev. bras. educ. med., 43(2), 216-224. http://www.scielo.br/scielo.php?script=sci_arttext\&pid=S0100-55022019000200216\&tlng=pt.

Doherty, D. et al. (2018) What can we learn from problem-based learning tutors at a graduate entry medical school? A mixed method approach. BMC Med Educ, 18(96), 1-12. doi.org/10.1186/s12909-018-1214-2.

Fermozelli, J. A., Cesaretti. M. L. R \& Barbo. M. L. P. (2017) Blended learning strategies in teaching general pathology at a medical course. J. Bras. Patol. Med. Lab, 53(3), 202-209. doi.org/10.5935/1676-2444.20170032.

Foina, A. (2011) Métodos de aquisição de dados quantitativos na internet: o uso da rede como fonte de dados empíricos. Ciência \& Trópico, 30(2), 283-296. https://periodicos.fundaj.gov.br/CIC/article/view/778.

Freeman, S. et al. (2014) Active learning increases student performance in science, engineering, and mathematics. Proceedings of the National Academy of Sciences - PNAS, San Francisco, 23. doi.org/10.1073/pnas.1319030111.

Freitas, R. A. M. D. Ensino por problemas: uma abordagem para o desenvolvimento do estudante. Educação e Pesquisa, São Paulo, 38(2), 403-418. http://www.scielo.br/pdf/ep/v38n2/aop478.pdf.

Freitas, H., Janissek, R., Moscarola, J. (2004) Dinâmica do processo de coleta e análise de dados via web. CIBRAPEQ - Congresso Internacional de Pesquisa Qualitativa, Taubaté, p. 12. http://gianti.ea.ufrgs.br/files/artigos/2004/2004_157_CIBRAPEQ.pdf.

Goergen, P. (2008) Educação superior entre formação e performance. Avaliação: Revista da Avaliação da Educação Superior, Sorocaba, 13(3), 809-815. https://www.redalyc.org/pdf/2191/219114874010.pdf.

Google apps script. (2017) Overview of Google Apps Script. 2017. https://developers.google.com/apps-script/overview.

Google. (2012) Introducing Google Drive. 2012. https://developers.googleblog.com/2012/04/introducing-google-drive-and-google.html .

Ibrahim, M. et al. (2018) The Effectiveness of Problem-based Learning in Acquisition of Knowledge, Soft Skills During Basic and Preclinical Sciences: Medical Students' Points of View. Acta informatica medica: AIM: journal of the Society for Medical Informatics of Bosnia \& Herzegovina: casopis Drustva za medicinsku informatiku BiH,(26), 119-124. doi.org/10.5455/aim.

Jiménez-saiz, R. e Rosace, D. (2019) Is hybrid-PBL advancing teaching in biomedicine? A systematic review. BMC medical education, 19(1)1-8. https://www.ncbi.nlm.nih.gov/pmc/articles/PMC6591981/pdf/12909_2019_Article_1673.pdf.

Junior, J. A. S. \& kanikadan, P. Y. S. (2019) A possível presença de sintomas psicossomáticos em estudantes de medicina e sua relação com método ABP (Aprendizado Baseado Em Problemas). 2019. Trabalho de Conclusão do Curso (Bacharel em Medicina) - Universidade Estadual do Sudoeste da Bahia, Vitória da Conquista.

Kalaian, S. \& Kasim, R. (2017) Effectiveness of various innovative learning methods in health science classrooms: a meta-analysis. Adv in Health Sci Educ, (22) 1151-1167. https://doi.org/10.1007/s10459-017-9753-6.

KhoshnevisasL, P. et al. (2014) Comparison of Problem-based Learning With Lecture-based Learning. Iranian Red Crescent Medical Journal. (16). https://europepmc.org/article/PMC/4082522.

Lacerda, F. C. B., \& Santos, L. M. (2018) Integralidade na formação do ensino superior: metodologias ativas de aprendizagem. Avaliação, Campinas, Sorocaba, 23 (3) 611- 627. http://www.scielo.br/pdf/aval/v23n3/1982-5765-aval-23-03-611.pdf. 
Marques, L. M. N. S. R. (2018) As metodologias ativas como estratégias para desenvolver a educação em valores na graduação em enfermagem. Escola Anna Nery, 22(3). http://www.scielo.br/pdf/ean/v22n3/pt_1414-8145-ean-22-03-e20180023.pdf.

Maya, P. E. U., Gonzalez, J. G. \& Ocampo C. J. L. (2017) Aprendizagem baseada em problemas para o ensino de PLCs na Universidade Tecnológica de Altamira. PASSEIO. Rev. Iberoam. Investig. Desenvolvimento. Educ, Guadalajara, 8(15), 566-581. http://www.scielo.org.mx/scielo.php? script=sci_arttext\&pid=S2007-74672017000200566\&lng=es\&nrm=iso.

Morais, A. G. (2012) Políticas de avaliação da alfabetização: discutindo a Provinha Brasil. Rev. Bras. Educ., 17 (51) 551-572. http://www.scielo.br/scielo.php?script=sci_arttext\&pid=S1413-24782012000300004\&lng=en\&nrm=iso.

Neves, C. E. B. (2007) Desafios da educação superior Sociologias. Sociologias, (17), 14-21. http://www.scielo.br/pdf/soc/n17/a02n17.pdf.

Oliveira, P. M. P. et al. (2012) Uso do filme como estratégia de ensino-aprendizagem sobre pessoas com deficiência: percepção de estudantes de enfermagem. Esc. Anna Nery, Rio de Janeiro, 16(2), 297-305. http://www.scielo.br/scielo.php?script=sci_arttext\&pid=S1414-81452012000200013\&lng=en\&nrm=iso.

Pinheiro, M., Sarrico, C. \& Santiago, R. (2011) Como os acadêmicos se adaptam a um ensino baseado em PBL numa licenciatura tradicional em Contabilidade. Revista de Contabilidade e Organizações, 5(13), 109-131. http://www.spell.org.br/documentos/ver/4947/how-academics-adapt-to-pblteaching-in-an-accounting-course/i/en.

Projeto pedagógico do Curso superior de Tecnologia em Estética e Cosmética. (2017) Curso Superior de Tecnologia em Estética e Cosmética. Campo Grande, Universidade Anhanguera - Uniderp. https://www.uniderp.br/uniderp/pdf/mec/matriz/PPC_Estetica_Cosmetica_KLS2.pdf.

Savery, J. R. (2006) Overview of Problem-based Learning: Definitions and Distinctions. Interdisciplinary Journal of Problem-Based Learning. doi.org/10.7771/1541-5015.1002.

Silva, E. V. M. et al. (2008) A formação de profissionais de saúde em sintonia com o SUS: currículo integrado e interdisciplinar. Brasília: Núcleo de Gestão do Trabalho e Educação na Saúde do CONASEMS.

Silva, F. F., Paiva, Y. G. \& Araújo, A. O. (2018) O ensino contábil na perspectiva da aprendizagem baseada em problemas. Revista Contemporânea de Contabilidade (UFSC), Florianópolis, 15(36) 188-210. doi.org/10.5007/2175-8069.2018v15n36p188.

Wang, Q. et al. (2016) Developing an integrated framework of problem-based learning and coaching psychology for medical education: a participatory research. BMC medical education, (2). doi.org/10.1186/s12909-015-0516-x.

Zahid, M. et al. (2016) Comparison of the problem based learning-driven with the traditional didactic-lecture-based curricula. International Journal of Medical Education. (7) 181-187. https://europepmc.org/article/PMC/4912697. 